\title{
Effet de l'addition de Lithioxine sur la croissance des génisses nourries à l'ensilage de prairie naturelle
}

\author{
JF Chesnel 1, JP Andrieu 2 \\ 'Néolait-Codislait, Direction Technique et Recherche, 22120 Yffiniac ; 2INRA, Laboratoire Valeur Alimentaire, \\ Theix, 63122 St-Genès-Champannelle, France
}

Dans les régions où la prairie naturelle constitue l'essentiel des ressources fourragères, la qualité de conservation des ensilages directs est souvent insuffisante. Elle peut être améliorée par l'addition de conservateur (JP Andrieu et al, 1990, INRA Prod Anim, 3, 67-73).

Trois ensilages ont été préparés à partir d'une même prairie naturelle récoltée au 1er cycle de végétation, en coupe directe, au domaine INRA d'Orcival (F 63210 Rochefort-Montagne) à $1000 \mathrm{~m}$ d'altitude. Les remorques ont été alternées pour chaque traitement : sans conservateur (T0), addition d'acide formique $(2 / 3)+$ formol (1/3) à la dose de $3,4 \mathrm{l} / \mathrm{t}$ de fourrage vert (T1), addition de Lithioxine (formiate de calcium $39 \%$, nitrite de sodium $23 \%$, hexaméthylène tétramine $14 \%$ ) à la dose de $2 \mathrm{~kg} /$ tonne (T2).

Trois lots de 12 génisses de race laitière (Holstein) pesant en moyenne $300 \mathrm{~kg}$ ont été constitués et maintenus en stabulation libre dans les mêmes conditions pendant la durée des 9 semaines d'expérience. Pendant l'essai, chaque ensilage a été distribué seul avec un aliment minéral.
Dans l'ensilage T0, la fermentation lactique est dominée par les fermentations productrices d'acide acétique et d'alcool. L'abaissement lent et insuffisant du $\mathrm{pH}$ et l'action de la flore butyrique ont favorisé la protéolyse. L'incorporation d'acide formique-formol et de Lithioxine permet une nette amélioration de la qualité de la conservation.

Les quantités de matière sèche, ingérées par les génisses, ne sont pas sensiblement différentes entre traitements. En revanche, le gain de poids vif des génisses ayant reçu l'ensilage sans conservateur est significativement inférieur $(P<0,05)$ à ceux des génisses ayant reçu les ensilages avec conservateur T1 et T2.

L'efficacité alimentaire, qui peut être appréciée par le gain de poids vif par $\mathrm{kg}$ de MS ingérée, a été respectivement de $85 \mathrm{~g}, 120 \mathrm{~g}$ et $110 \mathrm{~g}$ pour les ensilages T0, T1 et T2. La valeur azotée des ensilages a conditionné pour une large part leur valorisation par les génisses. Compte tenu de son efficacité et des avantages liés à son utilisation (produit solide distribué avec un micro granulateur), la Lithioxine enrichit la gamme des conservateurs d'ensilage.
T1

Ensilages
teneur en MS (\%)
$\mathrm{pH}$
$\mathrm{N}$ soluble $(\% \mathrm{~N}$ total)
acide lactique $(\mathrm{g} / \mathrm{kg} \mathrm{MS})$
acide acétique $(\mathrm{g} / \mathrm{kg} \mathrm{MS})$
acide butyrique $(\mathrm{g} / \mathrm{kg} \mathrm{MS})$
alcools totaux ( $\mathrm{g} / \mathrm{kg} \mathrm{MS})$
Génisses :
quantités ingérées $(\mathrm{kg} \mathrm{MS} / \mathrm{jour})$
gain de poids vif (g/jour)

Valeurs a et b différentes à $P<0,05$
T2

19,5

4,0

59,3

86,4

40,5

1,1

11,3

7,44

$806^{b}( \pm 145)$ 